\title{
EL CONCEPTO METAFÓRICO EN LA POESÍA DE SOR JUANA INÉS DE LA CRUZ: \\ UNA COMPARACIÓN TEXTUAL SHAKESPERIANA
}

POR

\author{
NORMAN LUNA \\ University of Nebraska at Omaha
}

Los sonetos de Shakespeare ejemplifican la mejor poesía manierista de la época isabelina en Inglaterra, y los de Sor Juana lo mejor del Barroco novohispano (Paz 74). Tanto el concepto petrarquesco, que "usually evoked the qualities of the disdainful mistress; and the devoted lover, often in highly exaggerated terms", como el concepto metafisico, que "applied wit and ingenuity to 'a combination of dissimilar images, or discovery of occult resemblances in things apparently unlike", son muy evidentes en la obra de ambos poetas ("Conceit"). La claridad poética de Shakespeare es pronunciada, (Levi 100) y la lucidez de Sor Juana la distingue entre los grandes poetas de la lengua ( $\mathrm{Paz}$ 625). Condiciones poco favorables para el teatro en México sin duda dictaron que escribiera Sor Juana Inés pocas obras teatrales en comparación con su compatriota, Juan Ruiz de Alarcón, quien pasó su vida creativa en España, aunque sin gran reconocimiento de su genio. Como en el caso de Shakespeare, son sus poemas de amor los que definen a Sor Juana como poeta, incluso "los de amistad amorosa" ( $\mathrm{Paz} 623$ ). Esta idealización platónica del amor en la literatura, según se expresa en el De Amore de Marsilio Ficino, era "un bien común de las personas civilizadas" en los siglos XVI y XVII (Paz 279). El modernamente analizado conflicto psíquico encontrado en Shakespeare y Sor Juana era, en su época, sublimado como la trascendencia de la naturaleza contemplativa del amor (Paz 137-138).

En la glosa sobre la visión del alma (142), Sor Juana declara a la virreina de México, a quien llama Lysi, que el Amor le dio la vista espiritual cuando sus ojos inútiles ya no podían ver la luz que adoraban. Porque los gozos del alma son gloria sin igual a los ojos de la fe (Sor Juana 142). Así, en el soneto 14, Shakespeare pronostica:

But from thine eyes my knowledge I derive, And, constant stars, in them I read such art As truth and beauty shall together thrive, If from thy self to store thou wouldst convert. Or else of thee this I prognosticate:

Thy end is truth's and beauty's doom and date

(Shakespeare 1310).

En el apóstrofe del bardo a la dorada belleza de la juventud: "Shall I compare thee to a summer's day?/ Thou art more lovely and more temperate./Rough winds do shake the 
darling buds of May, ...” (18.1-3) promete un verano eterno en su verso. Esto llega a ser un tema central de los Sonnets (Levi 102), junto con las cualidades de franqueza audaz, lucidez y tabú que son peculiares en Shakespeare, así como en Sor Juana, y que se relacionan con la idealización neoplatónica. En el soneto 20, sobre la gracia de su joven amigo y patrocinador, el conde de Southampton, cuya hermosura "steals men's eyes and women's souls amazeth", Shakespeare también precede a Sor Juana al castigar la falsedad del otro sexo. Siendo que el varón está hecho "for women's pleasure" termina: "Mine be thy love, and thy love's use their treasure" (20.8,11-12).

Entonces el ojo del poeta pinta la forma de la belleza dentro de su corazón (24.1-2). Él es el vasallo desnudo del señor de su amor (26.1). En uno de sus más hermosos sonetos convoca "remembrance of things past ... /precious friends hid in death's dateless night,/ And ... love's long since cancelled woe ..." hasta que, cuando piensa en el amigo querido: "All losses are restored, and sorrows end" $(30.2,6-7,14)$. También desempeña un papel paternal: "As a decrepit father takes delight/To see his active child do deeds of youth,/..." (37.1-2). Como Safo por Platón, y la misma Sor Juana, Lord Southampton también es invocado como la décima musa, el numen de la inspiración: "Be thou the tenth Muse, ten times more in worth" (38.9). Y también como Sor Juana, lamenta Shakespeare las tristes separaciones que acompañan el amor; mientras que ambos poetas utilizan la antítesis del concepto literario con gran efecto (Levi 103). Escribe el bardo inglés: " $O$ absence, what a torment wouldst thou prove,/Were it not thy sour leisure gave sweet leave/To entertain the time with thought of love; ..." (175.1-2).

El cariño de Shakespeare hacia su noble patrocinador trascendía cualquier rivalidad sentimental que pudiera surgir entre ellos: "But here's the joy: my friend and I are one;/ Sweet flattery! then she loves but me alone" (42.13-14). Sor Juana le escribió muchos poemas cariñosos al consorte y al infante de su adorada virreina, mientras que muchos de sus versos más apasionados forman eco del mismo amor que caracterizaba al bardo inglés: "Así tu amor, con vínculo terrible,/el alma que te adora, Celia, informa;/con que su corrupción es imposible, ..." (183.9-11). El poeta atribuye a sus propios defectos esa época cuando se entibia el amor, puesto que no puede achacárselo al amor mismo: "To leave poor me thou hast the strength of laws,/Since why to love I can allege no cause" (49.13-14). Sor Juana Inés, al contrario, encuentra que ésta es la naturaleza del amor, tan lleno de ardores, solicitud, riesgos y llantos que "apaga con sus lágrimas su fuego". Y termina el soneto: "¿Qué razón hay de que dolor te cueste,/pues no te engañó Amor, Alcino mío,/sino que llegó el término preciso?" (184.1-3,8,12-14).

Aunque la hermosura fatídica del joven conde de Southampton recuerda la de Adonis y la de Elena, siempre invoca a Odiseo y Penélope también: "But you like none, none you, for constant heart" (53.14). Mientras que Sor Juana encuentra solamente una belleza efimera en el florecimiento de la rosa tan pronto marchita, Shakespeare halla en su dulce fragancia una promesa de la hermosura juvenil tan amada y destilada en el verso: "Sweet roses do not so:/Of their sweet deaths are sweetest odours made./And so of you, beauteous and lovely youth,/When that shall vade, by verse distills your truth" (54.11-14). Y también tiene: "So, till the judgment that yourself arise,/You live in this, and dwell in lovers' eyes" (55.13-14). El famoso soneto de Sor Juana sobre la rosa termina: "icon qué con docta muerte y necia vida,/viviendo engañas y muriendo enseñas!" (147.13-14). 
La norma de esta poesía cortesana era la de la hipérbole, adulación y exaltación (Paz 254). Así en su afición a Lord Southampton, el bardo inglés proclama su fiel esclavitud, como lo hace Sor Juana también en su devoción a la divina marquesa de la Laguna. "So true a fool is love that in your will,/Though you do anything, he thinks no ill, ..." (57.1314) musita el "esclavo triste" en su "infierno". En el caso de la poetisa, "los hijos del alma" que son los "partos del pecho" poéticos, también pertenecen a su gran señora: "Así, Lysi divina, estos borrones/que hijos del alma son, partos del pecho,/será razón que a ti te restituya; ..." (195.9-11). En verso inmortal Shakespeare resuelve preservar la memoria de "la belleza del dulce amor, el tesoro de su primavera, y su alba juvenil" $(63.4,8,12)$. A pesar del cansancio de toda la desilusión de la vida, el poeta no obstante renuncia a la muerte para ser fidedigno al amor (66.13-14). En su lira, "Amado dueño mío," por otra parte, Sor Juana Inés no puede definir la belleza del amado que sobrepasa todo lo sentido, ni puede su pluma explicar un bien indecible.

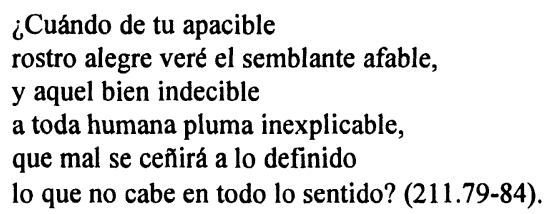

Pero aunque su cansada vida fallece de su ausencia, la esperanza brotará del llanto.

Como comenta Octavio Paz, incluso el amor propio es últimamente amor del ser amado:

\footnotetext{
El amor es una pasión, un padecimiento que nos hace salir de nosotros mismos en busca de la persona deseada y que, en un segundo movimiento, nos hace regresar a nosotros mismos e interrogar nuestra intimidad: buscamos allí la huella del objeto amado o contemplamos en silencio su fantasma (Paz 623).
}

Shakespeare termina un soneto sobre el amor propio con parecido sentimiento: "'Tis thee, my self, that for myself I praise,/Painting my age with beauty of thy days" (62.13-14). En la imagen de su propia hermosura, tan celebrada como la de Lord Southampton, Sor Juana encuentra solamente la ilusión del arte: "éste, en quien la lisonja ha pretendido/excusar de los años los horrores, ..." (145.5-6). El bardo lee en su espejo un ser propio "beated and chopt with tann'd antiquity" (62.10), mientras que Sor Juana Inés juzga que su retrato "es cadáver, es polvo, es sombra, es nada" (145.14). El poeta inglés cree la pintura falsa al imitar el rubor de la belleza: "And him as for a map doth Nature store,/To show false Art what beauty was of yore" (68.13-14). En las meditaciones sobre sus años el bardo ve en sí mismo: "Bare ruin'd choirs where late the sweet birds sang" (73.4). Y después de todo: "This thou perceiv'st which makes thy love more strong,/To love that well which thou must leave ere long" (73.13-14). En un romance pregunta Sor Juana: "Si es para vivir tan poco,/¿de qué sirve saber tanto?" (2.131-132). El amor alcanza una expresión mística cuando el poeta inglés lo encuentra fundido con la vida, y con su mismo ser: "Happy to have thy love, happy to die!" (92.12). Y también: “The summer's flow'r is to the summer 
sweet/Though to itself it only live and die; ..."(94.9-10). En las palabras de Sor Juana, son los celos la prueba del amor.

\author{
todos fingieron amor, \\ mas ninguno fingió celos. \\ Porque aquél puede fingirse \\ con otro color, mas éstos \\ son la prueba del amor \\ y la prueba de si mesmos (3.79-84).
}

Shakespeare reflexiona: "So shall I live, supposing thou are true,/like a deceived husband; ..." (93.1-2).

En la ausencia del ser amado, las canciones de los pájaros y las hermosas flores de la primavera son solamente un patrón y una sombra del amor para el bardo (98). En el soneto que sigue la sinestesia de color y fragancia en las flores del amor es tumultuosa y exuberante, en cuanto la violeta recuerda el hálito del ser amado y las tintas venas del amor; la azucena, una mano, y el cabello, los pimpollos de la mejorana. Entre las rosas unas se ruborizaban de vergüenza, las blancas de desesperanza, y otras del hálito rosado del amor, de donde robaban todas las flores dulzura o color (99). Cuando era nuevo el amor y estaba en su primavera, el poeta, como la filomela, acostumbraba saludarlo con sus cantos. Pero en el verano el empalago le detiene la lengua (102). Sor Juana Inés también reflexiona sobre la separación del amado:

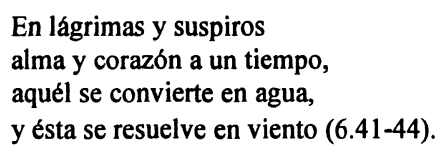

Para Shakespeare es el amor lo que confiere la inmortalidad en la hermosura del ser amado; en cuanto el frío del invierno sacude la soberbia del verano del bosque y la linda primavera se transforma en el amarillo otoño año tras año (104). El amor indisolublemente reúne la constancia, el afecto y la verdad (105): "So that eternal love in love's fresh case/ Weighs not the dust and injury of age ..." (108.9-10). Del alma amada escribe el poeta: "That is my home of love. If I have rang'd,/Like him that travels, I return again, ..." (109.13-14). Para el bardo la rosa aquí es un símbolo universal del amor (109.13-14); como para Sor Juana lo es de la belleza pasajera. "The marriage of true minds" de que escribe Shakespeare es la promesa del amor constante en la vida (116.1). Sus sentimientos exaltados cobran su sentido pleno a la luz de la influencia del neoplatonismo renacentista en la Inglaterra isabelina; así como fue el caso con Sor Juana en el mundo hispánico (Paz 282). En un soneto concluyente añade el poeta inglés que el rigor que causa el dolor en el amor tiene que terminar en el perdón mutuo (120).

Siguiendo la tradición de la poesía cortés (Paz 265-266), igual que Shakespeare, Sor Juana, en sus cadenas de amor, preferiría ser la esclava de su adorada virreina, María Luisa Manrique de Lara, en vez de ser reina ella misma (16.49-50). En el próximo de esta serie de romances, su afecto se transformaría en la vida misma para que la señora querida viviera para siempre (17.57-60). Y declara: 
Ser mujer, ni estar ausente, no es de amarte impedimento; pues sabes tú, que las almas distancia ignoran y sexo (19.109-112).

Teniendo en cuenta la larga aceptación cultural de la íntima amistad platónica, Sor Juana podía declararse, espiritualmente, un andrógino, en virtud de su virginidad y profesión religiosa $(\mathrm{Paz} 291)$. El haber amado la belleza juvenil hace al poeta inglés demasiado sabedor del pasar del tiempo, mientras que el amante se marchita y crece la dulce juventud (126). Como Sor Juana Inés, cuyo amor pastoril es señor así como señora, el bardo canta de la morena belleza de su querida también (127). Ella es la música (128), el paraíso y el infierno del celo (129), y aún incomparable: "My mistress' eyes are nothing like the sun" (130.1). Y si sus hechos son negros (131.13), sus ojos enlutados son como "the morning sun of heaven" $(132.3,5)$. En un romance Sor Juana le escribe a la condesa de Paredes en su cumpleaños: "que no impera en las deidades/el estrago de los siglos" (20.7-8). Así cuando la querida y hermosa doña María exige su tratado sobre la música, Sor Juana responde que es indigna de enseñar la música a un ángel (21.109). Entonces mil besos acompañan un dulce de nueces para la virreina, que le ha regalado una diadema emplumada a la célebre poeta (23).

Shakespeare lamenta la esclavitud del amor hacia la misma mujer que aprisiona a su más amable amigo junto con él (133.4). Puede haber existido la "Dark Lady" de los Sonnets, o puede haber sido solamente una idealización (Levi 107). En el caso de Sor Juana, al contrario, sus muchos sentimientos de estimación por el virrey de México siempre eran, según la estricta convención, formales en vez de íntimos (Paz 266). Por su parte, Shakespeare sentía que había perdido tanto a Southampton como a la belleza morena: "Him have I lost; thou hast both him and me;/He pays the whole, and yet am I not free" (134.13-14). Ambos poetas son capaces de usar el conceptismo literario meramente para un efecto diestro pero, en cualquier caso, sin el sentimento y sus intuiciones el efecto suena hueco. Después de dedicar dos sonetos (135-136) a juegos de palabras sobre el nombre Will, el bardo llama al amor un bobo ciego, que tiene los ojos: "anchor'd in the bay where all men ride" (137.6). Así finge creer las mentiras del amor: "Thus vainly thinking that she thinks me young,/... And age in love loves not to have years told" $(138.5,12)$.

Las culpas que Sor Juana Inés atribuye a los hombres en sus requerimientos de las mujeres, en la sátira filosófica que empieza: "Hombres necios que acusais ..." (92.1), Shakespeare las encuentra en su "female evil", porque de sus dos cariños: "the better angel is a man right fair,/The worser spirit a woman colour'd ill". Ella tenta a su "better angel" de su lado, y quisiera corromper a su santo a ser un diablo: "wooing his purity with her foul pride" (144.3-8). La poeta les pregunta a los hombres por qué quieren que las mujeres obren bien si las incitan al mal (92.7-8). Los hombres se quejan si se tratan mal, y se burlan si se quieren bien (92.27-28). En sus promesas y solicitaciones reúnen al diablo, la carne y el mundo (92.67-68).

El misticismo shakesperiano del "amor terrenal" que comenta Peter Levi con referencia a "The Phoenix and the Turtle" (214), es característico de la entera vena neoplatónica de los Sonnets también; así como lo es de todo lo que incluye Octavio Paz dentro de lo que 
llama la "poesía de amor" de Sor Juana (617). Para la monja "la profesión religiosa ha neutralizado a su sexualidad ...", y así su amor de los otros está idealizado y poetizado. (Paz 292) Para el bardo la naturaleza Tanto del hombre como de la mujer indica la expresión del amor, del cual piensa "with the same mystical intensity as John of the Cross thought of the love of God" (Levi 39). En un romance en que le responde a un caballero peruano que le dice que se haga hombre, Sor Juana le escribe que no se debe mirar como una mujer, siendo que no es una mujer que le pueda servir a alguien como mujer, porque su cuerpo, sin ninguna inclinación particular, es neutro o abstracto en cuanto a lo que el alma solamente recomienda (48.103-108).

En un romance que le envía de México, Sor Juana reitera la alabanza de su bella patrocinadora, la virreina, ya vuelta a España. La garganta de la real marquesa-condesa de Paredes, como un órgano musical de mármol, es un pasaje a los jardines de Venus (61.3739). Como en el caso de Shakespeare, cuyo patrocinio por el célebre joven conde de Southampton le facilitó el desarrollo poético y dramático (Levi 93), la amistad y la protección de las virreinas de la Nueva España hicieron de Sor Juana una poeta de renombre en todo el mundo hispánico cuando, de otra manera, hubiera vivido como murió, tiranizada por eclesiásticos fanáticos tan poderosos como cualquier señor grande del reino ( $\mathrm{Paz} 556$ ). Termina las endechas reales a la marquesa de la Laguna:

En fin, yo de adorarte

el delito confieso; si quieres castigarme, este mismo castigo será premio (82.33-36).

En las redondillas sobre un retrato de la hermosura de la virreina, Sor Juana Inés declara que la belleza de la marquesa es tan grande que su imagen solamente se puede contemplar como en un espejo (89.5-8). Porque un afecto como el que expresa la poeta no se debe a la gratitud sino a la dicha de una belleza tan conquistadora (90.37.40). Así escribe Octavio Paz sobre Marsilio Ficino, el inventor renacentista de la expresión amor platónico: "Para Ficino el amor, incluso en su forma inferior: atracción por la belleza del cuerpo, es siempre contemplativo y no es sensual o sexual" (Paz 279). Y excusándose de un silencio, escribe la poeta:

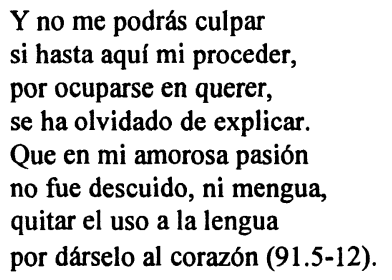

Aunque halla que la belleza divina de la virreina es inmortal aun en comparación con su retrato, el soneto/retrato de Sor Juana sobre sí misma es un himno de la desilusión barroca, como se ha observado. Shakespeare también encuentra que el buen parecer de su 
patrocinador excede en mucho cualquier representación, aunque reflexiona insistentemente sobre los estragos del tiempo que inevitablemente han de alcanzarlo a él, y últimamente hasta al joven barón de Titchfield (Levi 104).

Sor Juana no estaba tal vez tan desinteresada en la belleza y las riquezas como protesta en un soneto, aunque el saber era supremo para ella (146). Era, después de todo, una belleza opulenta y fabulosa, así como una poeta de renombre y una señora de la corte virreinal, incluso siendo monja. Siempre ha habido conventos para toda condición, estilo de vida y vocación, pero un establecimiento de tal categoría y elegancia sería inaudito actualmente. Estas señoras criollas religiosas administraban cómodas residencias privadas, con sus alumnas, sirvientas y esclavas personales, así como sus ocupaciones y presupuestos individuales; mientras que, en común, solamente observaban las requeridas funciones monásticas litúrgicas (Paz 354-355). Shakespeare también era aficionado a la hermosura, próspero, famoso, e íntimo de la clase alta, aunque odiaba a la aristocracia tanto como Sor Juana Inés a la jerarquía que la perseguía:

En perseguirme, Mundo, ¿qué interesas?

¿En qué te ofendo, cuando sólo intento

poner bellezas en mi entendimiento

y no mi entendimiento en las bellezas (146.1-4).

La poesía barroca es una idealización imaginativa en que el ingenio del poeta se expresa por medio del concepto metafórico (Paz 369-370). Otra característica que se destaca en la inigualable poesía amorosa de Shakespeare y, hasta cierto punto, de la de Sor Juana, es la pasión sublime que ilumina su verso. El inspirado prototipo del misticismo seráfico de San Juan de la Cruz, citado por Peter Levi, ya se ha notado. Así a veces está Shakespeare "all full with feasting" en la contemplación del ser querido, que es "as food to life", pero después está "clean starved for a look"; y termina el soneto: "Thus do I pine and surfeit day by day,/or gluttoning on all, or all away" (75.1,9-10,13-14). Sor Juana expresa un tema similar en las redondillas sobre el efecto irracional del amor:

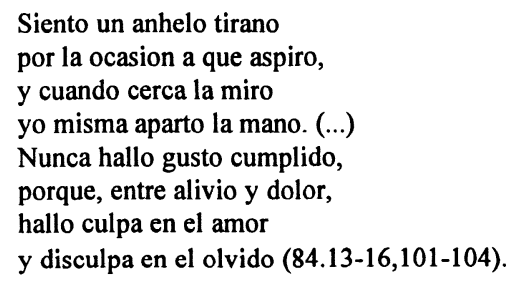

Los sonetos de Shakespeare que tratan del "poeta rival" son un tributo a su contemporáneo más ilustre, Christopher Marlowe (Levi 104-105), cuya influencia es notable en los tempranos dramas históricos del bardo. En su obra maestra, El sueño (216), Sor Juana imita a Luis de Góngora, el maestro español del Barroco extremo; pero su teatro muestra mucho más la poderosa influencia de su coetáneo, Pedro Calderón de la Barca, poeta filosófico también de logros magistrales y el último gran dramaturgo del Siglo de 
Oro (Paz 622). El concepto metafórico que caracteriza la poesía lírica de Sor Juana también fue la especialidad de otro gran escritor de la época, Francisco de Quevedo.

\section{Obras CONSUltadas}

Juana Inés de la Cruz. Lírica personal. México: Fondo de Cultura Económica, 1951. Levi, Peter. The Life and Times of William Shakespeare. New York: Holt, 1989 The Oxford Campanion to English Literature, $5^{\mathrm{a}}$ edición. 1985.

Paz, Octavio. Sor Juana Inés de la Cruz o Las trampas de la fe. Barcelona: Seix Barral, 1982.

Shakespeare, William. Sonnets. New York: Random House, 1952. 